\title{
Effect of chromatin condensation on frozen-thawed sperm DNA integrity in normozoospermic men
}

\author{
Golshan-Iranpour $F^{1,2}$, Zamani Rarani $F^{3}$, Dashti GR ${ }^{2,4}$ \\ 1. Associate Professor, Saint Maryam Fertility and Infertility Center, Shahid Beheshti Hospital, Isfahan, Iran. ORCID ID: \\ 0000-0003-3390-3233 \\ 2. Associate Professor, Department of Anatomical Sciences, School of Medicine, Isfahan University of Medical Sciences, \\ Isfahan, Iran. \\ 3. MSc Student, Department of Anatomical Sciences, School of Medicine, Isfahan University of Medical Sciences, Isfahan, \\ Iran. \\ 4. Associate Professor, Saint Maryam Fertility and Infertility Center, Shahid Beheshti Hospital, Isfahan, Iran. (Corresponding \\ Author), Tel: +98-3137929040, Email: dashti@med.mui.ac.ir, ORCID ID: 0000-0002-2725-6423
}

\begin{abstract}
Background and Aim: Sperm cryopreservation is a common technique used for management of male infertility. But this method has detrimental effects on sperm DNA and chromatin quality. Evaluation of different markers associated with the health of genetic material of sperm is beneficial for determination of the fertility of sperm. The aim of this study was to assess the effect of sperm chromatin condensation on frozen-thawed sperm DNA integrity in normozoospermic men.

Material and Methods: In this experimental study, 30 semen samples from normozospermia men were cryopreserved for two weeks with a common technique used in most infertility centers, at $-196^{\circ} \mathrm{C}$ and then thawed. Samples before and after freezing were evaluated for abnormal chromatin condensation, DNA denaturation and DNA fragmentation by toluidine blue (TB) staining, acridine orange (AO) staining and sperm chromatin dispersion (SCD) test respectively.

Results: Before freezing, we found a significant correlation only between abnormal chromatin condensation (evaluated by TB) and DNA denaturation (assessed by AO) ( $\mathrm{p}<$ 0.05). While after cryopreservation correlation was found between abnormal chromatin condensation and DNA denaturation and fragmentation $(\mathrm{p}<0.05)$.

Conclusion: Abnormal chromatin condensation can make DNA susceptible to denaturation and fragmentation.
\end{abstract}

Keywords: Sperm, Deoxyribonucleic acid, Chromatin, Normozoospermic

Received: Dec 24, $2018 \quad$ Accepted: May 12, 2019 


\title{
تاثير تراكم كروماتين بر تماميت DNA اسِرم فريز و ذوب شده در مردان نورموزواسِرم
}

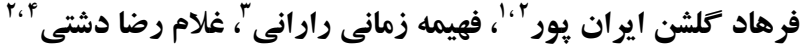

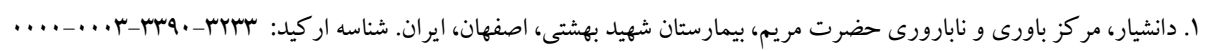

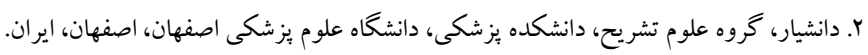

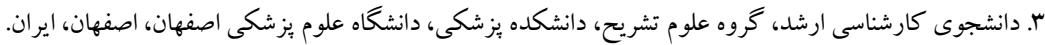

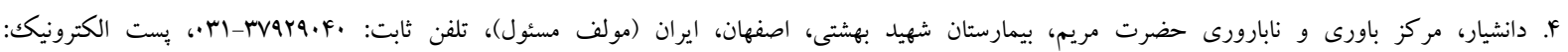

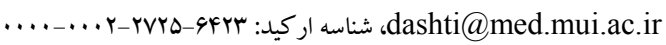

جكيده

زمينه و هدف: ذخيره ى انجماد سريع (Cryopreservation) اسبرم تكنيكى رايـج بـراى افرادى كـه در رابطه بـا مسئله ى

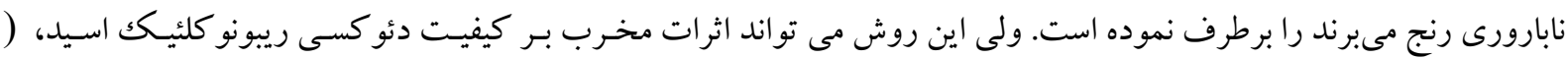

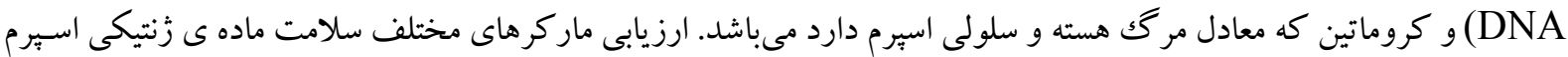
عوامل موثر در جهت تشخيص قدرت بارورى اسبرم، در درمان بيماران نابارورى است. در اين مطالعه، ارزش تشخيصى و بررسى

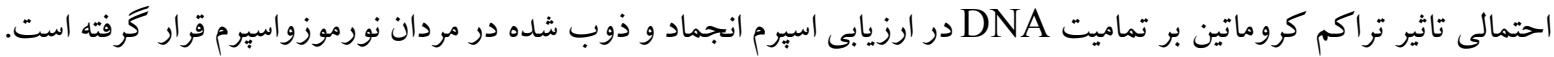
روش بررسى: در اين مطالعه ى تجربى، ·ب نمونه مايع منى مردان نورموزواسبرم به مدت دو هفته با تكنيك رايج در اكثر مر مراكز

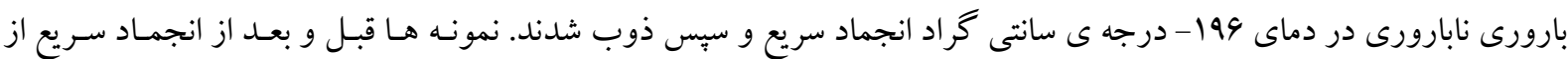

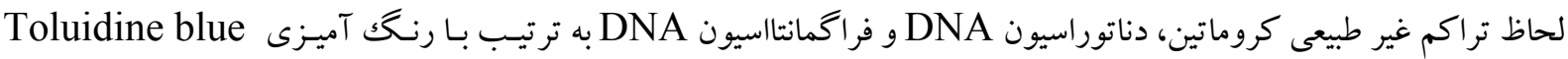

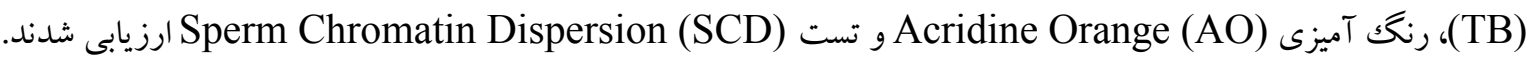

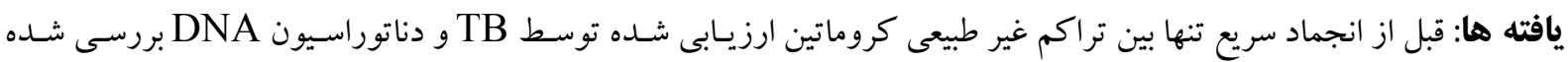

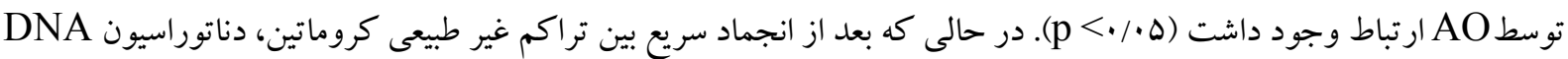

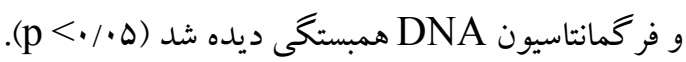
نتيجه كيرى: تراكم غير طبيعى كروماتين مى تواند DNA را مستعد دناتوراسيون و فراكمانتاسيون كند.

$$
\begin{aligned}
& \text { كليد وازه ها: اسيرم، دئو كسى ريبونو كلئيك اسيد، كروماتين، نورموزواسبرم }
\end{aligned}
$$

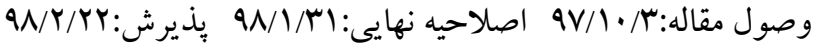


جنينى (I I) و... داشته باشد. هر جند مطالعاتى نيز وجود دارد

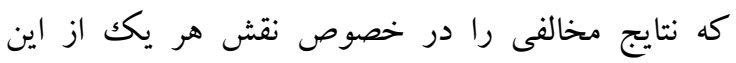

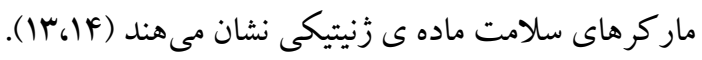

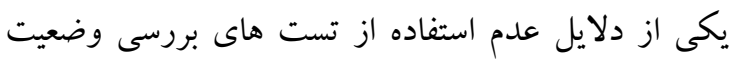

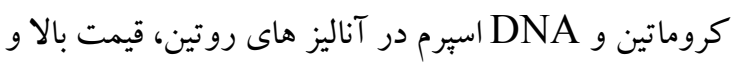
نياز به مهارت در انجام اين تست ها مى باشد. هدف ما از

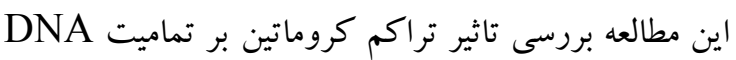
اسيرم انجماد و ذوب شده در مردان نورموزواسيرم مىباشد.

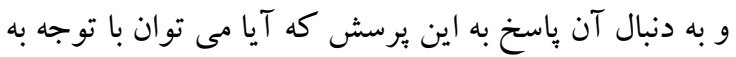

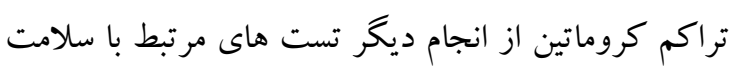
DNA

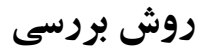

اين مطالعه، يكك مطالعه ى تجربى بود كه به شماره كد

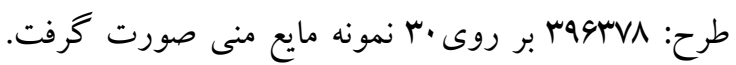

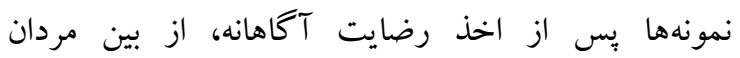
نورموزواسيرم مراجعه كننده به مركز فوق تخصصى بارورى نابارورى حضرت مريم(س) بيمارستان شهيد بهشتى اصفهان كه حداقل ץ-r روز مقاربت نداشته ، به صورت تصادفى انتخاب و در ظروف استريل جمع آورى شدند. آناليز اسيرم بر اساس دستورالعمل سازمان بهداشت جهانى (World WHO Health Organization هاى سمن در دماى اتاق به مدت ·r-r.r دقيقه قرار گرفته تا به حالت مايع تبديل شود.سبس قبل از فر آيند فريز و ويس از آن تستهاى سلامت كروماتين و DNA در كنار ساير تست هاى روتين انجام شد. اين مطالعه يِ از اخذ مجوز از كميته اخلاق دانشگاه علوم يزشكى اصفهان، درآزمايشگاه بافت شناسى گروه آناتومى دانشكده يزشكى اين دانشگاه و نيز مركز فوق تخصصى بارورى نابارورى حضرت مريم(س) بيمارستان شهيد بهشتى اصفهان انجام شد.

\section{روش انجماد و ذوب اسيرم}

\section{مقدمه}

نابارورى زوج هاى جوان بسيارى را تحت تاثير قرار داده است. فاكتورهاى مردانه در حدود •4 درصد از علل نابارورى دخالت دارند كه ·F درصد به تنهايى و ·r درصد در تر كيب با فاكتورهاى زنانه مى باشد (1). يكى از روش

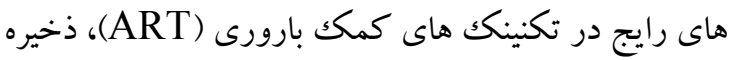

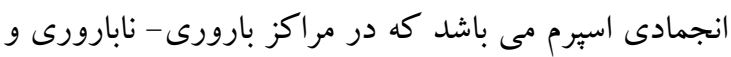

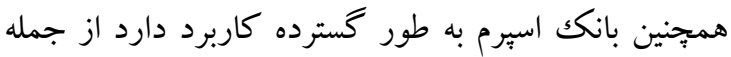

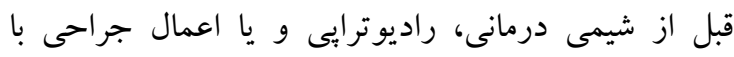

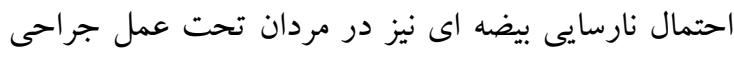

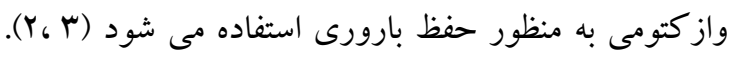
عليرغم مزاياى فراوان روش انجماد و ذوب مايع سمن در زمينه ى توليدمثل، اين روش اثرات مخرب بر سلول ها

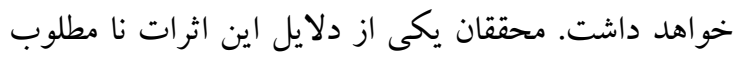

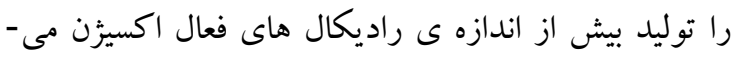

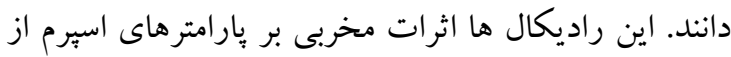
جمله حركت، بقا و كيفيت DNA و كروماتين اسبرم دارد (\$-4). در نتيجه بعد از انجماد انجام تست هاى بروسى كيفيت اسبرم توصيه مىشود تا اهداف درمانى با موفيقيت بيشترى محقق شود. مطالعات نشان دادهاند كه آسيب كروماتين و DNA در نابارورى تاثير گذار هستند. همجنين در نمونه هايى با بارامترهاى اسبرمى طبيعى همجنان احتمال

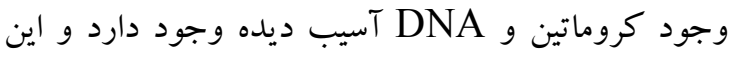
يارامترها نمىتواند نشان دهنده ى وضعيت كروماتين و اسبرم باشند.در نتيجه انجام تست هاى ديخر به ويزّه در زوج هايى با نابارورى بدون علت نامشخص توصيه شده

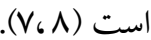
تخمك و رويان قادر به اصلاح برخى از آسيب هاى موجود

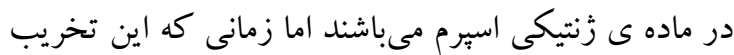
ها از حد آستانه بالاتر باشند قدرت اصئر اصلاح قادر به ياسخ كويى نيست (9). مطالعات نشان دادهاند ميزان بالاى آسيب DNA

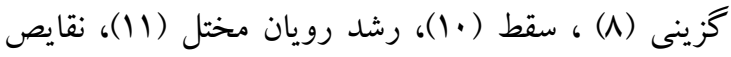


استيكك اسيد به نسبت ץ:(1) فيكس گرديد. سبس هر نمونه

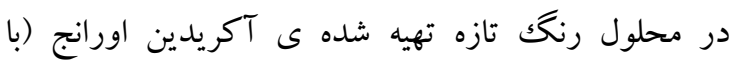

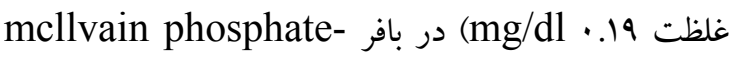
(pH=4) citrate

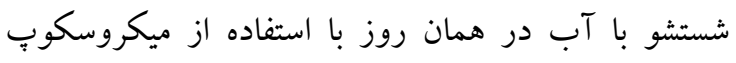

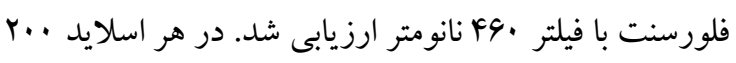

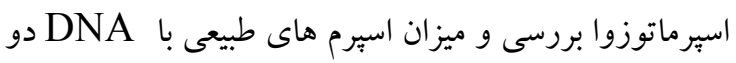

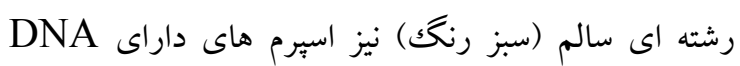

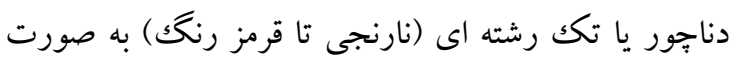
درصد كزارش شد (IV، IN).

\section{بروسى اسيرم ها از لحاظ فراكمانتاسيون DNA}

(Sperm Chromatin Dispersion (SCD))

ارزيابى نمونه هاى سمن از نظر فراگمانتاسيون DNA با Dان

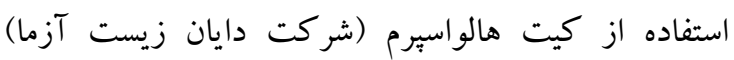

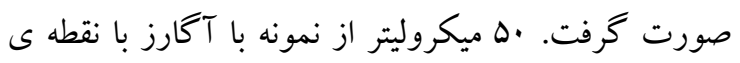
ذوب بإيين مخلوط و بر روى لام شيشه اى قرار داده شد.

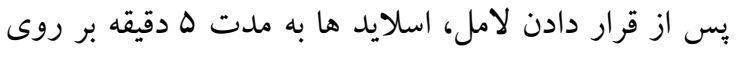

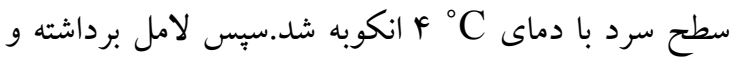
اسلايد در محلول دناتوره كننده و بس از آن در محلول ليز كننده غوطه ور شد. بِ از شستشو با آب مقطر، با استفاده از محلول هاى اتانول با غلظت صعودى (•V،، .9 و ..1\%)

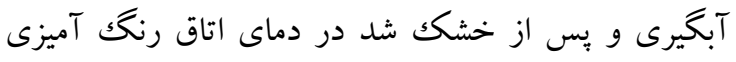
مجددا با آب مقطر شتشو داده شد. با استفاده از

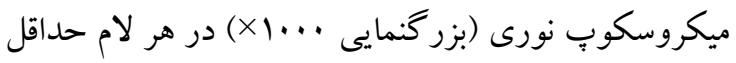

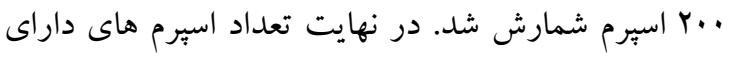

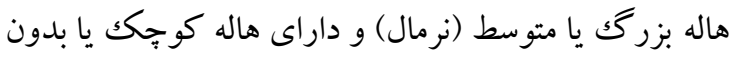

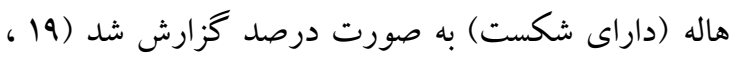
״س از جمع آورى داده ها آناليز آمارى با استفاده از نرم

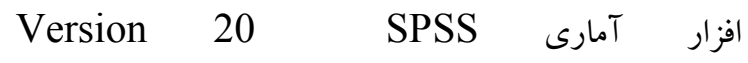
مورد تجزيه و تحليل قرار گرفت. (Inc.,Chicago.IL) در اين مطالعه از آزمون همبستخى بيرسون ( Pearson's
فريز اسبرم با استفاده از محيط تجارى(Sperm vitrolife) Freeze Solution, Vitrolife, Goteborg, انجام شد. جهت فريز با محيط تجارى فريز Sweden) Vitrolife محيط مخلوط و به داخل كر ايو ويال كد گذارى شده انتقال

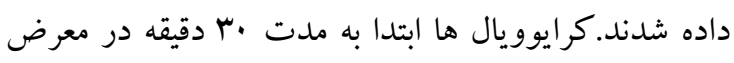

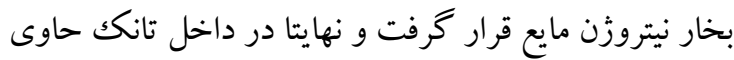

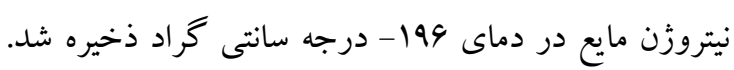

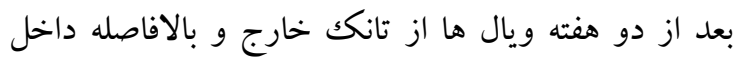
ظرف حاوى نيتروزن مايع و نهايتا به مدت لـ ادقيقه در حمام

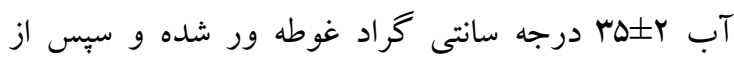
لحاظ كيفيت كروماتين و DNA مورد ارزيابى قرار كرفتند.

Toluidine Blue (TB) رنك آميزى تولويدين بلو جهت ارزيابى تراكم كروماتين اسبرم استفاده

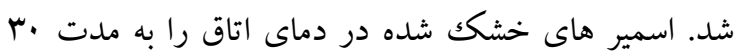

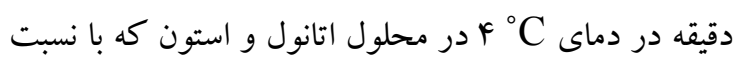

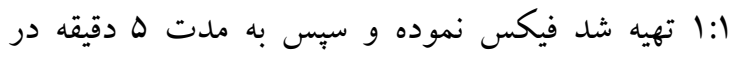

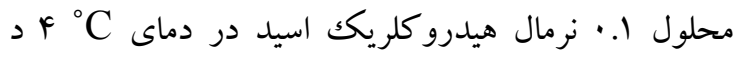

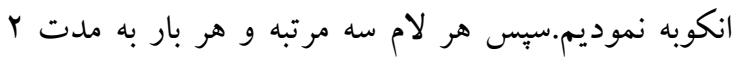

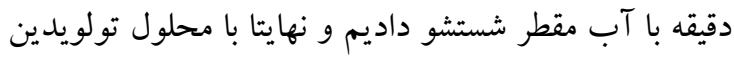

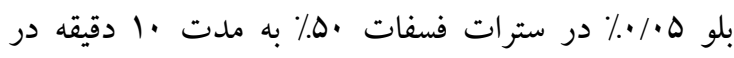

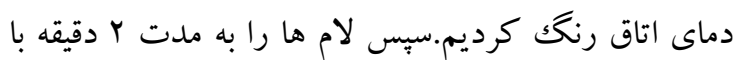

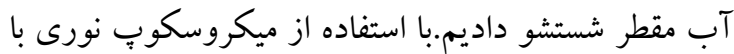

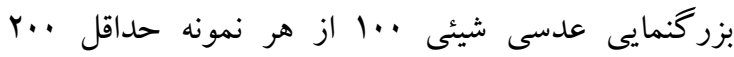

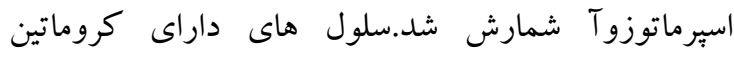

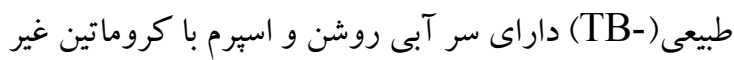

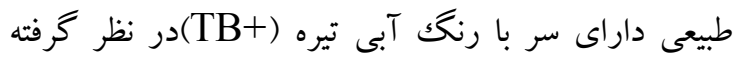

شدند (19) (19)

\section{رنك آميزى (AO) رe}

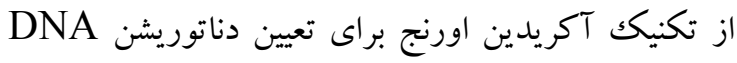

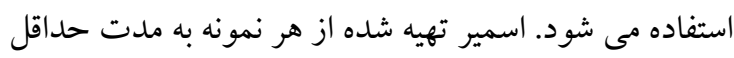

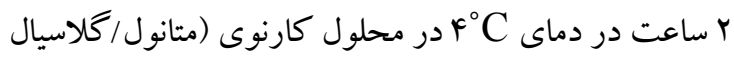


كروماتين و اسربرم هاى داراى دناتوراسيونDNA ارتباط وجود داشت (ه •/•> p) و نسبت به قبل از فريز اين ارتباط داري معنى دارتر بود. همبِنين قبل از فريز نتايج حاصل از ارزيابى درصد اسبرم

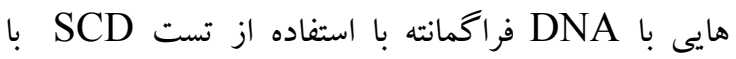
درصد اسرِم هايى با تراكم غير طبيعى كروماتين ارتباط

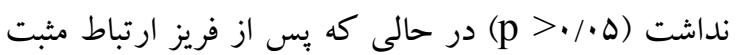

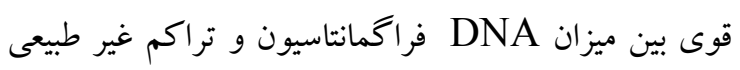

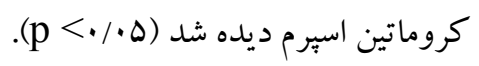

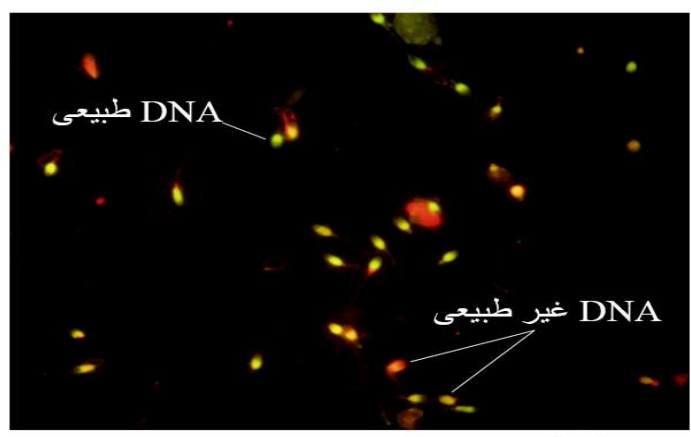

بعد از فريز
(Correlation Coefficient عنوان سطح معنى دارى در نظر گرفته شد. نتايج بر اساس جدول ا و شكل هاى r- ا، در نمونه هاى تازه و قبل از فر آيند فريز و ذوب، بين تراكم غير طبيعى كروماتين

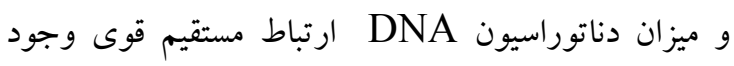

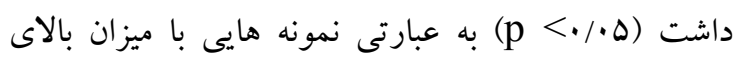
اسبرم هاى غير طبيعى از لحاظ تراكم كروماتين، درصد

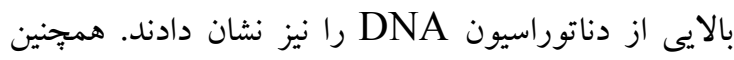
يس از فريز بين ميزان اسبرم هايى با تراكم غير طبيعى

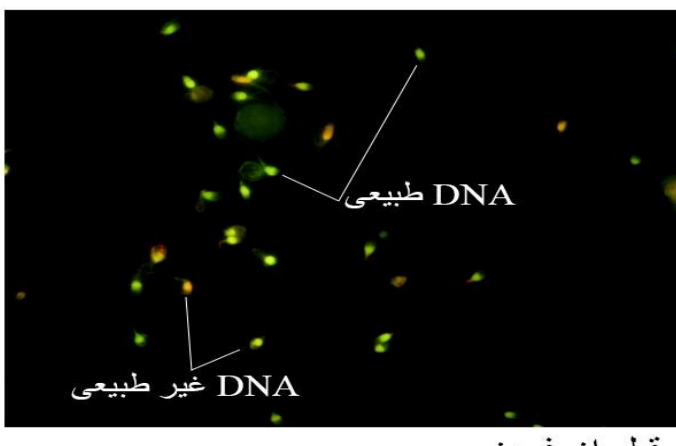

قبل از فريز

شكل ا: رنك آميزى آكريدين اورنج. نمايش اسيرم با DNA سالم دو رشته اى (سبز رنك) و DNA دناتوره تكك رشته اى (نارنجى تا قرمز رنكگ) با

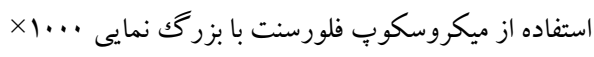

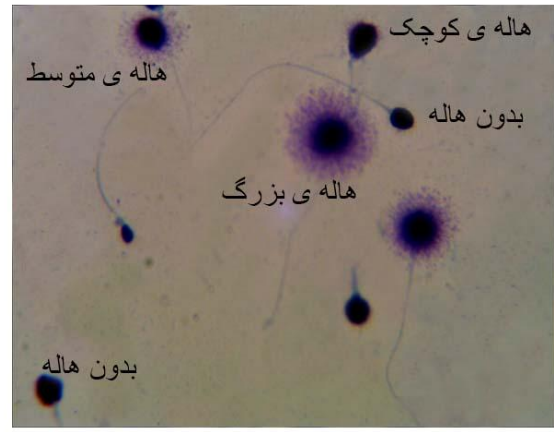

بعد از فريز

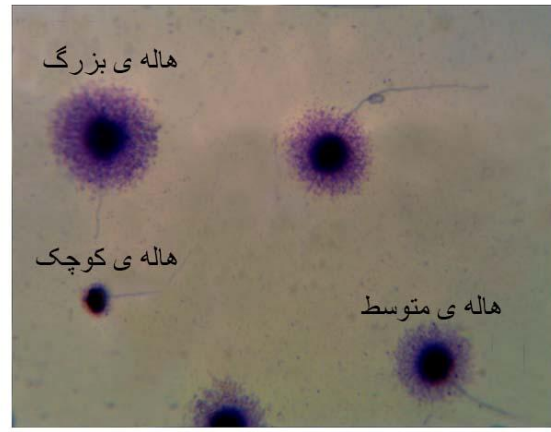

قبل از فريز

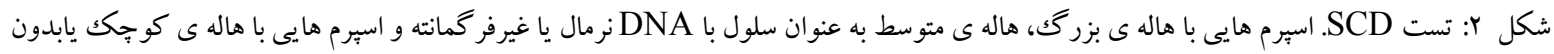

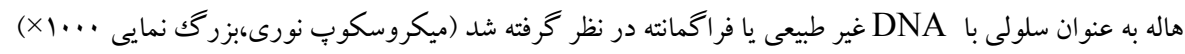




\begin{tabular}{|c|c|c|c|c|}
\hline \multicolumn{4}{|c|}{ \% تراكم غير طبيعى كروماتين (TB) } & \\
\hline \multicolumn{2}{|c|}{ بعد از فريز } & \multicolumn{2}{|c|}{ قبل از فريز } & \\
\hline $\mathrm{r}$ & $P$ value & $\mathrm{r}$ & $\mathrm{P}$ value & \\
\hline$\cdot 19 \cdot 1$ & $\% \cdots$ & $\cdot / 0 \cdot r$ & $\% \Delta$ & (AO) DNA دناتوراسيون ) \\
\hline .1999 & 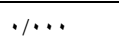 &.$/$ MAY &.$/ 191$ & \% فراكمنتاسيون SCD) DNA) \\
\hline
\end{tabular}

در سال Y.IV نيز در مطالعه اى بر روى أF مرد

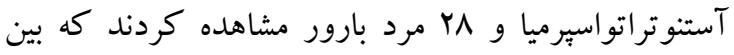
درصد اسبرم هايى با ساختار غير طبيعى كروماتين ارزيابى

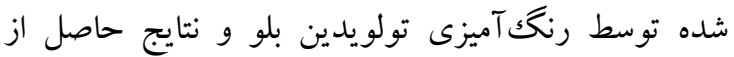

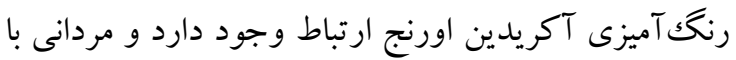
سطوح بالاى ساختار كروماتينى غيرطبيعى درصد بالاترى از دناتوراسيون DNA و پيارامترهاى اسبرمى غير طبيعى دارند

مطالعات كذشته نشان داده اند كه فرآيند فريز عليرغم مزاياى فراوان بر بارامتر هاى اسبرمى نظير حركت، بقاو نيز

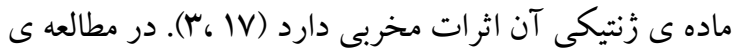
نشان داد كه غذاى بر كلستروال به تنهاى يا به همراه آهن ،

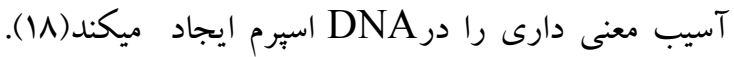

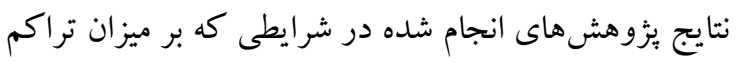

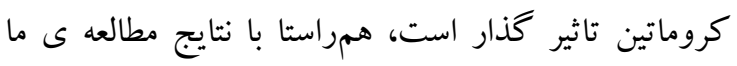

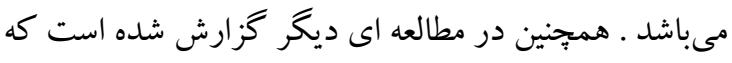
در افراد سيگارى كيفيت نمونه ى منى از لحاظ ميزان حر كت و بقا اسبرم ها كاهش يافته و ميزان فراخمانتاسيون DNA از لحاظ آمارى در مقايسه با افر اد غير سيكارى بيشتر

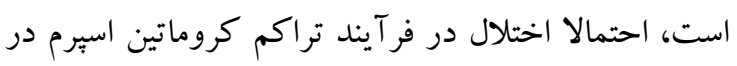
افراد سيكارى، DNA را نسبت به آسيب مستعد مى كند.

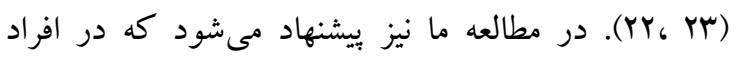
نورموزواسبرم، فرآيند فريز و ذوب ب با تخريب ساختار

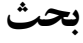
تراكم بيشتر كروماتين اسبرم انسانى در مقايسه با ساير سلول-

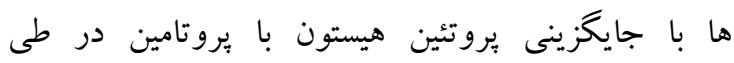

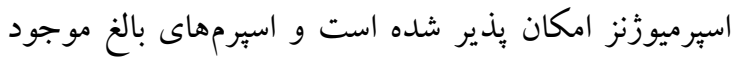
در دم إيديديم داراى كروماتين با تراكم بالا در مقايسه با بال

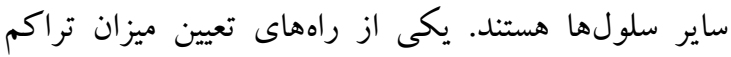
كروماتين سنجش سطوح بروتامين يا هيستون با روش هاى

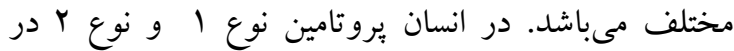
تراكم ماده ى زنتيكى اسبرم نقش دارند. كروماتين متراكم

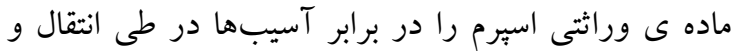
رسيدن به اووسيت حفظ مى كند •(Y). نتايج مطالعه ما نيز نشان داد كه قبل از فر آيند فريز اسيرم انسانى، تراكم غير طبيعى كروماتين با ميزان دناتوراسيون DNA هاى داراى DNA فر گمانته و درصد اسرِم هاى داراى تراكم غير طبيعى كروماتين هم ارتباطى وجود نداشت. بعد از فريز و ذوب نمونه ها، تراكم غير طبيعى كروماتين علاوه دناتوراسيون DNA با ميزان فراخمانتاسيون نيز مرتبط بود. به عبارتى بعد از فريز افزايش ميزان اسيرمهايى با تراكم غير

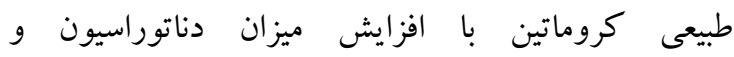
فراخمانتاسيون همر اه بود. تراكم غير طبيعى كروماتين ممكن است با مستعد كردن ماده ى زنتيكى اسبرم نسبت به عوامل آسيب رسان داخلى و ورئي

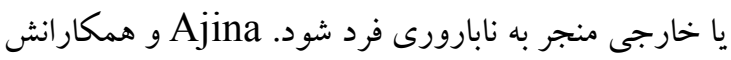




\section{نتيجه تيرى}

با توجه به نتايج بررسى ماركرهاى مختلف سلامت كروماتين و DNA اسيرم قبل و بعد از فرآيند فريز ما براس بيشنهاد مى كنيم كه تراكم غير طبيعى كروماتين اسيرم مى -

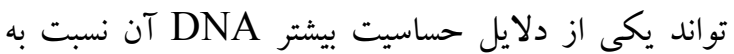
آسيب باشد. به نظر مىرسد در مردان نورموزواسبرم قبل از فريز، ارزيابى وضعيت تراكم كروماتين با TB مى تواند

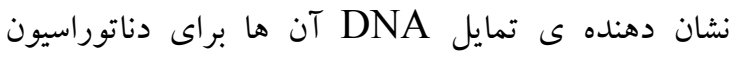

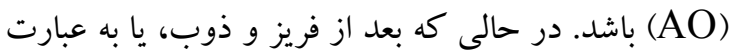

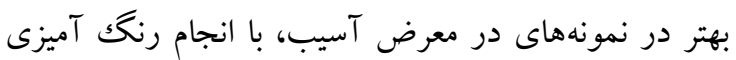
نسبتا ساده و ارزان TB مى توان با اطمينان بيشترى به دمريه وضعيت سلامت SCD و AO) DNA ) بي برد. ما بيشنهاد مى كنيم كه مطالعات آينده با افراد غير نورمواسيرم نظير اليگگ اسيرميا، تراتواسِرميا و ... انجام شود.

از معاونت محترم تحقيقات و فن آورى دانشكاه علوم

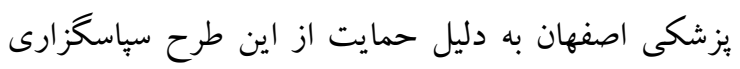

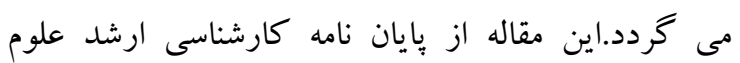

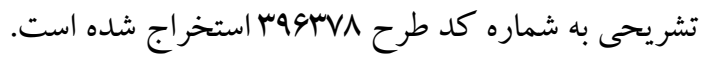

متراكم كروماتين اسيرم، DNA آن را نسبت به آسيب ها مستعد كرده است. مطالعات فراوان در خصوص تاثيرات تنش گرمايى بر بارامتر هاى اسبرم انجام شده است. Zhang و همكارانش در سال

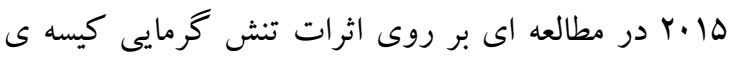

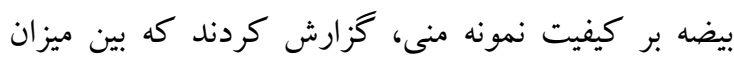

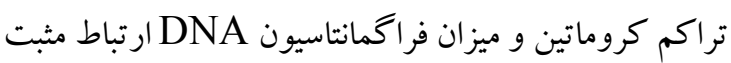

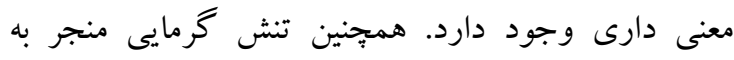

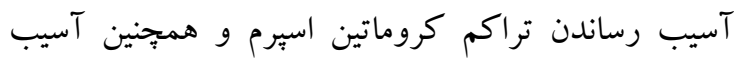
DNA

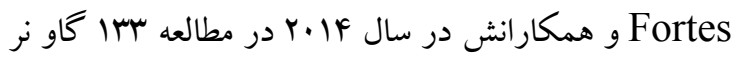
و با اندازه گيرى محتواى برو تامين اسبرم آن ها و مشاهده ى ارتباط آن با ميزان تخريب DNA گزارش كردند كه

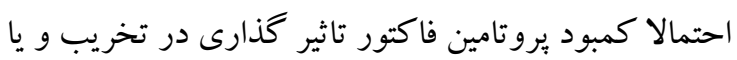
آسيب بذيرى DNA اين سلول ها مىباشد (Yه). همجِنين گزارش شده است كه ميزان هيستون هسته اسبرم

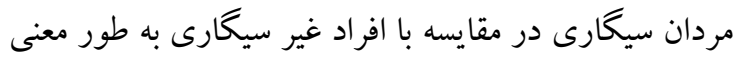
دارى بيشتر مىباشد و بين اين ميزان و ماركر هاى تنش اكسيداتيو ارتباط مثبت قوى وجود دارد. به عبارتى اين سلول ها در مردان سيكارى در مقايسه با افراد غير سيخارى نسبت به آسيبهاى ناشى از تنش اكسيداتيو مستعد تر هستند

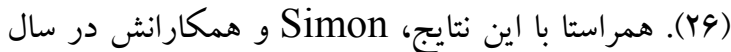

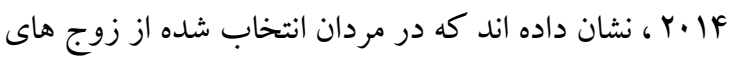
تحت درمان هاى كمكك بارورى، ميزان هيستون هاى باقى مانده در هسته اسبرم با تخريب DNA آن ها ارتباط

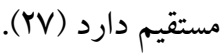
همجِنين در مطالعه ى Hosseinifar فر و همكارانش در درد سال هابrr، نشان داده اند كه در مردان كلوبوزواسبرميا سطح آسيب DNA، اندازه گيرى شده به وسيله ى chromatin structure assay (SCSA) يروتامين اسبرم ارزيابى شده با CMA3 ارتباط دارد (Y^). 


\section{References}

1. Jodar M, Soler-Ventura A, Oliva R, of Reproduction MB, Group DR. Semen proteomics and male infertility. J Proteomics 2017;162:125-34.

2. Keshtgar S, Iravanpour F, Gharesi-Fard B, Kazerooni M. Combined effect of Trolox and EDTA on frozen-thawed sperm quality. Iran J Med Sci 2016;41:230-7.

3. Naeini ZK, Bafrani HH, Nikzad H. Evaluation of ebselen supplementation on cryopreservation medium in human semen. Iran J Reprod Med 2014; 12:249-56.

4. Amidi F ,Pazhohan A, Nashtaei MS, Khodarahmian M, Nekoonam S. The role of antioxidants in sperm freezing: a review. Cell Tissue Bank 2016;17:745-56.

5. Toghiani S, Dashti GR, Roudbari NH, Roozbehani S. Effect of ascorbic acid and menthone on the caspase 3 in the sperm cells of acyclovir treated rats. Acta Medica 2016;32:1213-8.

6. Golshan Iranpour F, Fazelian K, Dashti GR. Thymoquinone as a natural spermostatic substance in reproductive medicine: an experimental study. Int J Reprod Biomed (Yazd) 2017; 15: 641-8.

7. Bungum M, Bungum L, Giwercman A. Sperm chromatin structure assay (SCSA): a tool in diagnosis and treatment of infertility. Asian J Androl 2011;13:69-75.

8. Sivanarayana T, Ravi Krishna C, Jaya Prakash G, Krishna K, Madan K, Sudhakar G, et al. Sperm DNA fragmentation assay by sperm chromatin dispersion (SCD): correlation between DNA fragmentation and outcome of intracytoplasmic sperm injection. Reprod Med Biol 2014;13:87-94.

9. Sakkas D, Alvarez JG. Sperm DNA fragmentation: mechanisms of origin, impact on reproductive outcome, and analysis. Fertil Steril 2010;93:1027-36.

10. Zidi-Jrah I, Hajlaoui A, Mougou-Zerelli S, Kammoun M, Meniaoui I, Sallem A, Brahem S, Fekih M, Bibi M, Saad A, Ibala-Romdhane S. Relationship between sperm aneuploidy, sperm DNA integrity, chromatin packaging, traditional semen parameters, and recurrent pregnancy loss. Fertil Steril 2016;105:58-64.

11.Simon L, Murphy K, Shamsi MB, Liu L, Emery B, Aston KI, et al. Paternal influence of sperm DNA integrity on early embryonic development. Hum Reprod 2014;29:2402-12.

12. Santos R, Palos-Ladeiro M, Besnard A, Porcher JM, Bony S, Sanchez W, et al. Relationship between DNA damage in sperm after ex vivo exposure and abnormal embryo development in the progeny of the three-spined stickleback. Reproductive Toxicology 2012;36:6-11.

13. González-Marín C, Gosálvez J, Roy R. Types, causes, detection and repair of DNA fragmentation in animal and human sperm cells. Int J Mol Sci 2012;13:14026-52.

14. Meseguer M, Santiso R, Garrido N, García-Herrero S, Remohí J, Fernandez JL. Effect of sperm DNA fragmentation on pregnancy outcome depends on oocyte quality. Fertil Steril 2011;95:124-8.

15. Cooper TG, Noonan E, Von Eckardstein S, Auger J, Baker HW, Behre HM, et al. world health organization reference values for human semen characteristics. Hum Reprod Update 2010;16:231-45.

16. Rahiminia T, Hosseini A, Anvari M, Ghasemi-Esmailabad S, Talebi AR. Modern human sperm freezing: effect on DNA, chromatin and acrosome integrity. Taiwan J Obstet Gynecol 2017;56:472-6.

17. Rarani FZ, Golshan-Iranpour F, Dashti GR. Correlation between sperm motility and sperm chromatin/DNA damage before and after cryopreservation and the effect of folic acid and nicotinic acid on post-thaw sperm quality in normozoospermic men. Cell Tissue Bank 2019;28:1-12. 
18. Ghasemi N, Dashti GhrR, Amoozgar F, Vaez SA . Effect of cholesterol,iron and vitamin e on protamine deficiency and DNA fragmentation of male rabbit sperm. J Isfahan Med Sch 2013;31:1769-78. [In Persian]

19. Tandara M, Bajić A, Tandara L, Bilić-Zulle L, Šunj M, Kozina V, et al. Sperm DNA integrity testing: big halo is a good predictor of embryo quality and pregnancy after conventional IVF. Andrology 2014;2:678-86.

20 .García-Peiró A, Martínez-Heredia J, Oliver-Bonet M, Abad C, Amengual MJ, Navarro J, et al. Protamine 1 to protamine 2 ratio correlates with dynamic aspects of DNA fragmentation in human sperm. Fertil Steril 2011;95:105-9.

21. Ajina T, Ammar O, Haouas Z, Sallem A, Ezzi L, Grissa I, et al. Assessment of human sperm DNA integrity using two cytochemical tests: Acridine orange test and toluidine blue assay. Andrologia 2017;49:1-6.

22. Yu B, Qi Y, Liu D, Gao X, Chen H, Bai C, et al.Cigarette smoking is associated with abnormal histone-to-protamine transition in human sperm. Fertil Steril 2014;101:51-7.

23. Taha EA, Ez-Aldin AM, Sayed SK, Ghandour NM, Mostafa T. Effect of smoking on sperm vitality, DNA integrity, seminal oxidative stress, zinc in fertile men. Urology 2012;80:822-5.

24. Zhang MH, Shi ZD, Yu JC, Zhang YP, Wang LG, Qiu Y. Scrotal heat stress causes sperm chromatin damage and cysteinyl aspartate-spicific proteinases 3 changes in fertile men. $\mathrm{J}$ Assist Reprod Genet 2015;32:747-55.

25. Fortes MR, Satake N, Corbet DH, Corbet NJ, Burns BM, Moore SS, et al. Sperm protamine deficiency correlates with sperm DNA damage in B os indicus bulls. Andrology 2014;2:370-8.

26. Hamad MF, Shelko N, Kartarius S, Montenarh M, Hammadeh ME. Impact of cigarette smoking on histone (H2B) to protamine ratio in human spermatozoa and its relation to sperm parameters. Andrology 2014;2:666-77.

27. Simon L, Liu L, Murphy K, Ge S, Hotaling J, Aston KI, et al. Comparative analysis of three sperm DNA damage assays and sperm nuclear protein content in couples undergoing assisted reproduction treatment. Human Reproduction 2014;29:904-17.

28. Hosseinifar H, Yazdanikhah S, Modarresi T, Totonchi M, Sadighi Gilani M, Sabbaghian M. Correlation between sperm DNA fragmentation index and CMA 3 positive spermatozoa in globozoospermic patients. Andrology 2015;3:526-31. 